\title{
When feedback holds us back
}

\author{
Diana Bath \\ University of Greenwich
}

\section{What is the difference between being opinionated and having an informed opinion?}

This is the question I asked my level 5 students recently, during a session in which I was introducing their next assignment and advising them on how to improve on their previous one; it's a question I habitually use at this point and, as always, it was met this time with blank faces. It is not that the students struggle to answer the question, although some undoubtedly do; it is rather that their feedback at levels 3 and 4 led them to believe that they weren't allowed to express opinions in assignments. When I suggest to them that it is possible to become informed by analysing the evidence and then drawing one's own interpretation of the research, the students express concerns about 'going off track' and not being able to find quotations to support what they want to say; similarly, when I explain that they can improve the quality of their academic writing through the use of reflection, the standard response is: "But I have been told to avoid opinions and how can I say what I think if I am not allowed to use 'l'?" The problem with this kind of feedback is that students become both constrained by the rules that are introduced to help them and preoccupied with the mechanics of what they can and can't do. Instead, they should be finding confidence through the use of academic conventions which liberate independent thought and support the development of their critical faculties. It seems that, by level 5 , many students have an imagined 'internal template' or 'formula' for essay writing which is tried and tested. As they progress towards level 6 , students have more at stake and are arguably less likely to risk original thinking in an assessed piece. However, they may be enticed to discuss their views in class, provided they can see the benefit of it for their own learning.

\section{The risks posed by assessed reflection}

From student course evaluation feedback, I have become increasingly aware that, for many students, the fact that the Reflective Journal is an assessed piece leads them to perceive it as yet another assessment hoop to be jumped through, if they are to meet the assessment criteria. I wonder how authentic a student's reflective voice can be, if students are assessed by pre-determined criteria? The trouble is that reflection is very subjective, and the marking of it doubly so. Not only are there inconsistent definitions of reflection, but also a lack of standards to assess and determine adequate reflection (Koole et al, 2011).

Educational philosophy continues to generate a variety of divergent ways of embracing selfreflection in order to emphasise 'purposeful critical analysis of knowledge and experience so as to achieve deeper meaning and understanding' (Lew and Schmidt, 2011:530).

In my opinion, as an educator of early years teachers, the professional requirement to develop reflective practice is paramount in course design for a number of subject areas. However, it is something that is best developed during tutorials, where face-to-face dialogue can work towards meaningful co-reflections. This method of developing originality and depth of thought is likely to produce a more authentic presentation of a student's voice. 


\section{What's in an opinion?}

Those students who struggle with academic writing at level 5 and 6 may do so as a result of over-generalised feedback given at levels 3 and 4, where they are told to stick to the point and substantiate their opinions with a reference. It does indeed seem counterproductive to tell students in their first year not to give personal opinions in their writing, but then, in their final year when everything is at stake, to say: 'Tell me what YOU think.' It is true that unwelcome sweeping statements often slip into students' work, but not all opinions are problematic. Opinions can also be seen as catalysts for debate, starting points for research questions and a very useful means of exploring ideas using critical analysis. Opinions are a valuable resource for those working to improve graduate study skills, but I have found that even well-informed students often doubt the validity of their views. To help students make connections between things they read and to nurture their skills at developing argument, I have built discussion into class time by introducing the reflective journal (essentially, a reading journal using a template to remind students of the need to take down certain details from their sources, to summarise their reading and to respond to it in their own words). In these journals, students have been encouraged to write reflections about what they read on their course as 'learning tools' (Lew and Schmidt, 2011). Subsequent tutorial discussion focuses on what critical reflection is and how critical argument may be used in academic writing to achieve originality. Such occasions are also useful moments for looking together at the assessment criteria and discussing developmental action points in relation to previous assignments.

The difference between being opinionated and holding an informed opinion rests on the ability to use evidence in the construction of knowledge. This is the fundamental process of learning and points to the need to attend to both the learning process and summative learning outcomes (Bath, 2011).

\section{Reference list}

Bath, D. (2012) 'Let's get personal: A call for personalised pedagogy.' Compass: Journal of Learning and Teaching 2 (3)

Koole,S., Dornan,T., Aper,L., Scherpbier,A., Valcke,M., Cohen-Schotanus,J., Derese,A., (2011) 'Factors confounding the assessment of reflection: a critical review.' BMC Medical Education 11, 104. Available at: http://www.biomedcentral.com/1472-6920/11/104 (Accessed: 10 April 2015).

Lew, M. and Schmidt, H. (2011) 'Self-reflection and academic performance: is there a relationship?' Advances in Health Sciences Education Theory Practice 16 (4), 529-545. 